\title{
Implementation outcomes of a culturally adapted diabetes self-management education intervention for Native Hawaiians and Pacific islanders
}

\author{
Ka'imi A. Sinclair ${ }^{{ }^{*}}\left(\mathbb{D}\right.$, Anna Zamora-Kapoor ${ }^{2}$, Claire Townsend-Ing ${ }^{3}$, Pearl A. McElfish ${ }^{4}$ and
} Joseph Keawe'aimoku Kaholokula ${ }^{3}$

\begin{abstract}
Background: Native Hawaiians and Pacific Islanders (NHPIs) experience a disproportionate burden of type 2 diabetes and related complications. Although diabetes self-management education and support (DSMES) interventions have generally yielded positive results, few NHPIs have been included in these studies, and even fewer studies have been evaluated using a randomized controlled trial design and/or implementation research methods. The purpose of this pilot study was to evaluate implementation outcomes of a culturally adapted diabetes self-management education intervention delivered by peer educators to Native Hawaiians and Pacific Islanders residing in Honolulu, Hawai'i.
\end{abstract}

Methods: In three study sites, the peer educators and 48 participants randomized to the intervention were invited to participate in the mixed methods implementation research. We used a convergent parallel design to collect implementation data including fidelity, feasibility, acceptability, appropriateness, adoption, and sustainability. Data were collected from class observations, participants' class feedback, and post-intervention focus groups with participants and peer educators.

Results: In 314 end-of-class feedback surveys, 97\% of respondents expressed that they were satisfied or highly satisfied with the class content and activities, 98\% reported that the classes and materials were very useful, $94 \%$ reported very applicable, and $93 \%$ reported materials were culturally appropriate. Respondents identified several aspects of the program as especially enjoyable: interactions with peer educators, meeting in groups, learning about other participants' experiences with diabetes, and the information presented in each class. Major themes that emerged from the end-of-intervention focus groups were the relevance of the educational materials, strategies to manage blood glucose, hands-on activities, cultural aspects of the program, including the stories and analogies used to convey information, and appreciation of the group format and peer educators.

Conclusions: Results from this research support a culturally tailored, peer educator approach to DSMES among NHPIs. Delivery of the Partners in Care program is feasible in health care and community settings and is a reimbursable DSMES program.

(Continued on next page)

\footnotetext{
* Correspondence: Kaimi.sinclair@wsu.edu

${ }^{1}$ Institute for Research and Education to Advance Community Health,

College of Nursing, Washington State University, 1100 Olive Way, Suite 1200,

Seattle, WA 98101, USA

Full list of author information is available at the end of the article
}

(c) The Author(s). 2020 Open Access This article is licensed under a Creative Commons Attribution 4.0 International License, which permits use, sharing, adaptation, distribution and reproduction in any medium or format, as long as you give appropriate credit to the original author(s) and the source, provide a link to the Creative Commons licence, and indicate if changes were made. The images or other third party material in this article are included in the article's Creative Commons licence, unless indicated otherwise in a credit line to the material. If material is not included in the article's Creative Commons licence and your intended use is not permitted by statutory regulation or exceeds the permitted use, you will need to obtain permission directly from the copyright holder. To view a copy of this licence, visit http://creativecommons.org/licenses/by/4.0/ The Creative Commons Public Domain Dedication waiver (http://creativecommons.org/publicdomain/zero/1.0/) applies to the data made available in this article, unless otherwise stated in a credit line to the data. 
(Continued from previous page)

Trial registration: Clinicaltrials.gov Identifier: NCT01093924 prospectively registered 01.20.09.

Keywords: Diabetes self-management education, Native Hawaiian, Pacific Islander, Culturally adapted, Implementation research, Implementation outcomes, Community-engaged research, Peer educator

\section{Background}

Native Hawaiians and Pacific Islanders (NHPIs) experience a disproportionate burden of type 2 diabetes and related complications [1-5]. Among NHPIs in Hawaii, the prevalence of type 2 diabetes ranges from 19 to $22 \%$, [3] and it is the fourth-leading cause of death [3]. The extent of unmanaged diabetes among NHPIs is evident in the large number of reported medical complications and preventable hospitalizations related to type 2 diabetes $[3,5,6]$.

Type 2 diabetes has been recognized as one of the most challenging chronic illnesses to manage $[7,8]$. Early detection, treatment, and appropriate self-management (e.g., healthy eating, regular exercise, and medication use) are critical to reducing the risk of complications and improving quality of life [9]. Two landmark clinical trials have demonstrated that tight control of blood glucose can significantly reduce the risk of diabetes complications $[10,11]$. Every $1 \%$ reduction in A1C (a measure of glycemic control using levels of glycosylated hemoglobin) leads to a $14 \%$ reduction in the risk of all-cause mortality and myocardial infarction, and a $37 \%$ reduction in the risk of microvascular complications.

Interventions that promote diabetes self-management education and support (DSMES) have proven effective at improving glycemic control and encouraging lifestyle behaviors that can reduce the risk of diabetes complications and improve quality of life. DSMES aims to support informed decision-making, self-care behaviors, problem solving, and active collaboration between patients and their healthcare team [12]. The clinical goal for $\mathrm{A} 1 \mathrm{C}$, an average of blood glucose over 3 months, is $<7 \%$ to prevent microvascular complications [9]. NHPIs are more likely than members of other populations to have $\mathrm{A} 1 \mathrm{C}>8 \%$, [5] have high energy intake, be physically inactive, and be overweight or obese [13-18]. Given the disproportionate burden of diabetes [3] and challenges in managing diabetes [5], identifying appropriate DSME $\mathrm{S}$ interventions for NHPIs is a public health priority. Although DSMES interventions have generally yielded positive results, few NHPIs have been included in these studies, and even fewer studies have been evaluated using a randomized controlled trial design and/or implementation research methods [3]. Therefore, in 2011, Partners in Care was implemented in Honolulu, Hawai'i as a randomized controlled trial to evaluate the effectiveness of a DSMES intervention on glycemic control and self-management knowledge and behaviors among NHPIs.

This paper describes the evaluation of the Partners in Care implementation to understand the process of delivering a culturally adapted DSMES intervention delivered by trained peer educators in low-resource community and clinic settings. Implementation research is used to evaluate strategies that may optimally increase adoption and implementation of evidence-based practices and treatments in real-world settings [19]. It is a multidisciplinary method that evaluates implementation from the perspective of the users of research [20]. Users may include healthcare systems or providers who want to identify how to best integrate an evidence-based treatment into their particular context; organizations and communities who want to understand contextual adaptations that will improve the implementation of evidence-based practices; and participants in health promotion and disease prevention research [19]. Understanding facilitators and challenges to program implementation can inform the transferability, scalability, and dissemination of effective programs to other populations and settings [21, 22]. Proctor and colleagues [23] describe a taxonomy of 8 conceptually distinct implementation outcomes - acceptability, adoption, appropriateness, feasibility, fidelity, implementation cost, penetration, and sustainability. Our study evaluated, and this paper presents the results of, acceptability, adoption, appropriateness, feasibility, fidelity, and sustainability. These findings may be used to inform future implementation of Partners in Care with other NHPIs and in other populations and settings.

\section{Methods}

\section{Partners in Care Intervention Development and Delivery}

The Partners in Care intervention was adapted from previously evaluated DSMES interventions conducted with American Indians in the Southwest [24] and with African Americans and Latinos in Detroit, Michigan [25]. Adaptation procedures have been detailed elsewhere [26-28]. Briefly, 4 focus groups with 38 NHPI community members to assess facilitators and challenges to self-management of diabetes and interest in a groupbased educational intervention informed adaptations. Major focus group themes included multi-level difficulties in adherence to self-management behaviors, such as 
an eating plan recommended for glucose control, increased physical activity to lose or maintain a healthy weight, and lack of knowledge about the importance of glucose control to prevent complications. These themes were similar to those found among other populations the authors have worked with, [29] and strategies to address several challenges were already included in the curriculum. The focus groups themes and feedback from a community-academic steering committee [30] and 3 NHPI peer educators were combined with evidencebased American Diabetes Association clinical guidelines for blood glucose, A1C, blood pressure, and lipids [31] and Social Cognitive Theory [32] to inform the 12lesson Partners in Care curriculum (Table 1).

The authors provided a 4-h study protocol and curriculum implementation training to the three NHPI peer educators and provided technical assistance throughout the study. One peer educator worked for a Native Hawaiian community organization as a community-health worker, and 2 peer educators worked in Federally Qualified Health Centers, one as a health educator and the other as a registered dietician. The peer educators were well positioned to deliver Partners in Care because they had just completed delivery of a weight loss education intervention in their communities and received prior training in group facilitation, intervention research, behavior change strategies, survey administration, and recruitment and retention methods.

Participants received a $\$ 20$ gift card for each data collection visit, a copy of the curriculum, and incentives during each class that were relevant to the topic of the class. For example, a pill box was offered during Lesson 2: Medicine and Glucose Balance; a stretch band was offered during Lesson 5: Move More, Sit Less!; and a colander to rinse and drain fat from cooked ground beef was provided in Lesson 7: Diabetes and Cholesterol. Informational brochures and recipes from the American Diabetes Association were also included in the curriculum as supplemental material. The study protocol was approved by the University of Hawai'i Committee on Human Studies and the Native Hawaiian Health System Institutional Review Board.

\section{Partners in Care Intervention Outcomes}

Clinical and behavioral outcomes from the Partners in Care intervention have been described in detail elsewhere [28]. Briefly, a total of 82 NHPI were recruited, gave written informed consent, and completed the baseline assessment that was developed for this study (Supplementary File 1). Participants were randomly assigned to either the intervention or a wait list control group who received the same intervention after the final follow up survey. At 3 months, there were significant baseline

Table 1 Partners in Care 12 weekly 1-h curriculum topics and content

\begin{tabular}{|c|c|}
\hline Topic & Content \\
\hline $\begin{array}{l}\text { Lesson 1: Glucose Balance Makes } \\
\text { a Difference }\end{array}$ & $\begin{array}{l}\text { Description and illustrations of what blood glucose and A1C numbers mean; recommended goals for blood } \\
\text { glucose and } \mathrm{A} 1 \mathrm{C} \text {; how to lower blood glucose. }\end{array}$ \\
\hline $\begin{array}{l}\text { Lesson 2: Medicine and Glucose } \\
\text { Balance }\end{array}$ & $\begin{array}{l}\text { Description and brochures for each diabetes medication; possible side effects; brief description of how each } \\
\text { medicine works in the body to lower blood glucose; how to treat hypoglycemia; why it is important to take } \\
\text { medication as prescribed and to tell provider about side effects. }\end{array}$ \\
\hline $\begin{array}{l}\text { Lesson 3: Food and Glucose } \\
\text { Balance }\end{array}$ & $\begin{array}{l}\text { How various types of foods can affect blood glucose; strategies to keep blood glucose balanced throughout the } \\
\text { day. }\end{array}$ \\
\hline $\begin{array}{l}\text { Lesson 4: Plan Meals for Glucose } \\
\text { Balance }\end{array}$ & How to plan healthy meals for blood glucose balance; how to count carbohydrates and read labels. \\
\hline Lesson 5: Move More, Sit Less! & $\begin{array}{l}\text { Increase physical activity through discussion of challenges to exercise; skills training through role playing, and } \\
\text { behavior therapy using goal setting, reinforcement, modeling, and identification of non-food rewards. }\end{array}$ \\
\hline $\begin{array}{l}\text { Lesson 6: Diabetes and a Healthy } \\
\text { Heart }\end{array}$ & $\begin{array}{l}\text { Description of how diabetes affects the heart; how to control high blood pressure; recommended goals for } \\
\text { blood pressure. }\end{array}$ \\
\hline $\begin{array}{l}\text { Lesson 7: Diabetes and } \\
\text { Cholesterol }\end{array}$ & $\begin{array}{l}\text { Description of total cholesterol, } \mathrm{HDL}, \mathrm{LDL} \text {, and triglycerides; foods that contain which types of cholesterol; how } \\
\text { to control high cholesterol; recommended goals for lipids. }\end{array}$ \\
\hline $\begin{array}{l}\text { Lesson 8: Healthy Feet Keep You } \\
\text { Going! }\end{array}$ & $\begin{array}{l}\text { Importance of checking one's feet every day; how to check one's feet; getting feet checked by provider; how to } \\
\text { identify appropriate shoes to avoid injury to feet; what to do if you have a sore that won't heal. }\end{array}$ \\
\hline $\begin{array}{l}\text { Lesson 9: Stress, Depression, and } \\
\text { Diabetes }\end{array}$ & $\begin{array}{l}\text { Description of the relationship between diabetes, stress, and depression; how to lower stress; how to know if } \\
\text { one is depressed; what to do for depression; } 3 \text { stress-reducing strategies. }\end{array}$ \\
\hline $\begin{array}{l}\text { Lesson 10: Preventing } \\
\text { Complications }\end{array}$ & $\begin{array}{l}\text { Discussion of other diabetes-related complications (dental, neuropathy, nephropathy, retinopathy) and how to } \\
\text { prevent or delay them. }\end{array}$ \\
\hline Lesson 11: Your Diabetes Team & $\begin{array}{l}\text { How to better communicate with one's healthcare team; whom to include in one's diabetes team; the roles of } \\
\text { each person; role playing to practice how to ask questions of providers. }\end{array}$ \\
\hline $\begin{array}{l}\text { Lesson 12: Living Well with } \\
\text { Diabetes }\end{array}$ & $\begin{array}{l}\text { Maintaining self-management activities in order to stay healthy with diabetes and prevent or delay complica- } \\
\text { tions; potluck meal of healthy foods during the final lesson. }\end{array}$ \\
\hline
\end{tabular}


adjusted differences between the 48 participants randomized to the Partners in Care intervention compared to the and 34 wait list control group participants in intent-to-treat $(p<0.001)$ and complete case analyses $(p<0.0001)$ for $\mathrm{A} 1 \mathrm{C}$, understanding $(\mathrm{p}<0.0001)$, and performing diabetes self-management $(\mathrm{p}<0.0001)$ [28]. The Partners in Care study adheres to CONSORT guidelines [28].

\section{Implementation research: study design, setting, and participants}

Three peer educators and 48 participants in the three study sites who were randomized to the Partners in Care intervention were invited to participate in the implementation research. A convergent parallel design was used throughout the intervention to collect implementation data to evaluate acceptability, adoption, appropriateness, feasibility, fidelity, and sustainability (Table 2). With a convergent parallel design, both qualitative and quantitative data are collected, each is analyzed separately, then the data are merged and interpreted together.

\section{Participant implementation measures}

To measure class attendance, participants signed in at the beginning of each class and these data were entered into a participant attendance database. To measure overall acceptability of each class, defined as satisfaction, usefulness, applicability, and cultural appropriateness, participants were asked to respond to 4 items at the conclusion of every class. General satisfaction with each class was rated as $1=$ highly unsatisfied; $2=$ somewhat unsatisfied; 3 =neither unsatisfied nor satisfied; $4=$ somewhat satisfied; or $5=$ highly satisfied. To rate the usefulness of each class and its materials, the applicability of information, and the cultural appropriateness of class materials, participants used the rating scale $1=$ not at all; 2 =somewhat; or 3 = very for each question. Participants were also asked to respond to 3 open-ended questions: 1) What information during the class did you find especially helpful?; 2) What goal did you set for this class?; and 3) Provide any other comments you would like to share about today's meeting. After the final class, research staff conducted a 1-h focus group with each group of intervention participants to assess their satisfaction with the intervention, the usefulness and applicability of the information provided, and the perceived impact of the intervention on diabetes self-management knowledge and behaviors. To discourage socially desirable answers, peer educators were not present during these focus groups.

\section{Peer educator implementation measures}

To measure fidelity to the study protocol, two research staff concurrently but independently observed 4 random classes of each peer educator ( $n=12$ classes). Each research staff member was trained by the principal investigator to complete a checklist of critical intervention behaviors and materials to be delivered during each class to monitor: 1) fidelity to the curriculum, 2) participants' questions, 3) information added by peer educators, and 4) research staff's overall impressions of participant understanding and satisfaction with content and activities. During each class, research staff followed along in the curriculum to assess fidelity to the curriculum content. Fidelity was rated on a 1 to 5 scale, with $1=$ did not follow curriculum at all ( $0 \%$ fidelity); 2 = followed very little of curriculum (up to $30 \%$ fidelity); 3 =followed at least half of the curriculum (50\% fidelity); 4 =followed most of the curriculum (up to $80 \%$ fidelity); $5=$ followed all of curriculum (100\% fidelity). While peer educators were trained to adhere to the study protocol and deliver the curriculum as written, they were provided flexibility to incorporate relevant analogies and examples to appropriately convey the information to their groups. Additional information and/or strategies implemented during the study were documented by peer educators and research staff. Research staff's overall impressions of participant understanding of content and activities was ranked as $1=$ no one understood; $2=$ very few understood; $3=$ some understood; $4=$ most understood; $5=$ all understood. Overall impressions of participant satisfaction with content and activities was ranked as $1=$ not satisfied at all; $2=$ somewhat satisfied; $3=$ mostly satisfied; 4 = very satisfied.

After the intervention concluded, all 3 community peer educators participated in a focus group that solicited their perceptions of the cultural relevance, acceptability of the intervention materials, appropriateness and feasibility of Partners in Care to improve diabetes selfmanagement in NHPIs, and factors that enabled or challenged intervention implementation. The focus group was conducted as an open, informal discussion, with the academic principal investigator audio-recording peer educators' remarks.

\section{Data analysis}

All focus groups were audio-recorded, transcribed verbatim, and analyzed using Atlas ti 5.0 (Scientific Software Development, Berlin, Germany, 1998). Miles and Huberman's [33] method of content analysis, which involves categorizing statements and marking them to reflect concepts or themes, was applied qualitative data. Two coders reviewed the data separately to develop thematic categories based on the topics of the focus group guide. Data reduction was accomplished by selecting, simplifying, abstracting, and coding data according to the preliminary schema. Matrices were developed along thematic lines, and 
Table 2 Measurement of implementation outcomes for Partners in Care participants and peer educators

\begin{tabular}{|c|c|c|c|}
\hline $\begin{array}{l}\text { Implementation } \\
\text { Outcome }\end{array}$ & Definition & $\begin{array}{l}\text { Partners in Care Data } \\
\text { Source }\end{array}$ & $\begin{array}{l}\text { Partners in Care } \\
\text { Timepoint }\end{array}$ \\
\hline \multicolumn{4}{|l|}{ Participants } \\
\hline \multirow[t]{4}{*}{ Acceptability } & \multirow[t]{4}{*}{$\begin{array}{l}\text { Satisfaction, usefulness, applicability, and cultural appropriateness of } \\
\text { intervention materials and content }\end{array}$} & 4-item ranked questions & $\begin{array}{l}\text { End of each of } 12 \\
\text { classes }\end{array}$ \\
\hline & & 3 open-ended questions & $\begin{array}{l}\text { End of each of } 12 \\
\text { classes }\end{array}$ \\
\hline & & Attendance & $\begin{array}{l}\text { Beginning of each } \\
\text { of } 12 \text { classes }\end{array}$ \\
\hline & & Focus groups & $\begin{array}{l}\text { End of final class in } \\
\text { each site }\end{array}$ \\
\hline \multirow[t]{2}{*}{ Adoption } & \multirow[t]{2}{*}{ Intention, initial decision, or action to try self-management behaviors } & 3 open-ended questions & $\begin{array}{l}\text { End of each of } 12 \\
\text { classes }\end{array}$ \\
\hline & & Follow-up data collection & $\begin{array}{l}\text { 3-months post- } \\
\text { baseline data } \\
\text { collection }\end{array}$ \\
\hline \multirow[t]{2}{*}{ Appropriateness } & \multirow[t]{2}{*}{$\begin{array}{l}\text { Perceived fit, relevance, or compatibility of the evidence- based practice for a } \\
\text { given consumer }\end{array}$} & Participation and retention & $\begin{array}{l}\text { Beginning of each } \\
\text { of } 12 \text { classes }\end{array}$ \\
\hline & & Focus groups & $\begin{array}{l}\text { End of final class in } \\
\text { each site }\end{array}$ \\
\hline \multicolumn{4}{|l|}{ Peer Educators } \\
\hline Acceptability & $\begin{array}{l}\text { Satisfaction with aspects of the intervention (e.g., content, complexity, } \\
\text { comfort, delivery, and credibility) }\end{array}$ & Focus group & $\begin{array}{l}\text { End of the final } \\
\text { class }\end{array}$ \\
\hline Adoption & $\begin{array}{l}\text { Intention, initial decision, or action to try an evidence-based practice; initial } \\
\text { implementation }\end{array}$ & Delivery of intervention & $\begin{array}{l}\text { Throughout } \\
\text { intervention }\end{array}$ \\
\hline Appropriateness & $\begin{array}{l}\text { Perceived fit, relevance, or compatibility of evidence-based practice in a given } \\
\text { setting and/or perceived fit of the program to address a particular issue or } \\
\text { problem }\end{array}$ & Focus group & End of final class \\
\hline Feasibility & $\begin{array}{l}\text { Extent to which a new treatment or innovation can be successfully used or } \\
\text { carried out within a given setting; enabling factors and challenges to } \\
\text { implementation }\end{array}$ & Focus group & End of final class \\
\hline Fidelity & $\begin{array}{l}\text { Degree to which an intervention was implemented as it was prescribed in } \\
\text { the original protocol }\end{array}$ & $\begin{array}{l}\text { Direct observation of peer } \\
\text { educators by research staff }\end{array}$ & $\begin{array}{l}\text { Throughout } \\
\text { intervention }\end{array}$ \\
\hline \multicolumn{4}{|c|}{ Organization/Community } \\
\hline Sustainability & $\begin{array}{l}\text { Extent to which a newly implemented treatment is maintained or } \\
\text { institutionalized within a community or service setting's ongoing, stable } \\
\text { operations }\end{array}$ & $\begin{array}{l}\text { Peer educators, } \\
\text { communication with } \\
\text { adopters }\end{array}$ & $\begin{array}{l}\text { Upon study } \\
\text { completion }\end{array}$ \\
\hline
\end{tabular}

common themes were determined by grouping responses by the question that elicited them. For the end-of-class 3-item open-ended feedback surveys, responses and free-form notes were coded and enumerated, and the number of feedback forms with at least 1 written comment was reported. Descriptive statistics were used to examine participant characteristics, frequency of class participation, participant responses to the 4-item end of class survey to evaluate satisfaction, usefulness, applicability, and cultural appropriateness of class materials, and leading reasons for non-participation in classes. All data were then evaluated together to identify convergence and/or divergence between qualitative and quantitative data. All quantitative analyses were performed using SPSS version 20.0 (SPSS, Inc., Chicago, IL).

\section{Results}

\section{Participant implementation outcomes}

Demographic characteristics have been presented elsewhere [28]. As reported in our outcomes paper, of 82 enrolled participants, 48 were randomized to the Partners in Care intervention and 34 to the wait-list control group. Community partners requested randomizing more participants to the immediate intervention, rather than to the wait list control group. The average age was 53 years in the intervention group and 55 years in the control group. More than half of participants in each group were female and married, but intervention participants were more likely than controls to have a high school education or less. Control participants also had higher systolic blood 
pressure than those in the intervention group, but blood pressure was high in both groups.

\section{Class attendance and attrition}

Ten participants randomized to the intervention group dropped out before the study began because they could not attend scheduled classes due to competing demands of work and family. Four participants randomized to the intervention and three randomized to the wait list control group could not be reached to determine their reasons for dropping out of the study. Dropout was significantly associated with younger age $(p=0.001)$, but did not vary by site, sex, educational status, or baseline A1C [28]. The 34 intervention participants who remained in the study attended at least 1 class, $70 \%$ attended at least 9 classes, and 58\% attended all 12 classes. Class size ranged from 6 to 15 participants per site.

\section{Acceptability and adoption}

Intervention participants submitted 314 end-of-class feedback surveys. Survey response rates ranged from 74 to 95\% across all 12 classes; 97\% of respondents expressed that they were satisfied or highly satisfied with the class content and activities, 98\% reported that the classes and materials were very useful, $94 \%$ reported very applicable, and $93 \%$ reported materials were culturally appropriate. Respondents identified several aspects of the program as especially enjoyable: interactions with peer educators, meeting in groups, learning about other participants' experiences with diabetes, and the information presented in each class. For example, one participant stated, "Every time I come to class, I learn more about myself and what I need to do to control my blood glucose." Another wrote, "Now I can teach my daughter how to help me. She always asks how she can help." In response to the question, "What information did you find especially useful?" 98\% of respondents cited class content, including taste testing, label reading, role playing, medication brochures, and problem-solving activities (Table 3). Ninety-seven percent of participants who completed the feedback forms reported goals they set for themselves that were related to class topics.

\section{Appropriateness}

Three focus groups (i.e., 1 focus group in each site) were conducted with a total of 32 participants in the intervention group at the conclusion of the last intervention class. Of the focus group participants, $74 \%$ were female and mean age was 55 years. Major themes that emerged were the relevance of the educational materials and strategies proposed to better manage blood glucose, hands-on activities, cultural aspects of the program including the stories and analogies used to convey information, and appreciation of the group format and peer educators. Intervention participants reported that the curriculum materials were easy to read and understand, and that the intervention content was more educational and interactive than other DSMES classes they had attended. They reported that the story at the beginning of each class was a useful and effective way to introduce each class topic. They liked the group format because it allowed them to share information and experiences related to medication side effects, provider interactions, and family issues relevant to diabetes self-management. As one participant explained,

"I know I'm not alone now. I've gotten so much out of sharing my experiences and hearing about others' experiences with diabetes."

When asked which activities they liked most or found most useful, participants cited the educational brochures about diabetes medications, the intervention incentives (workout towel, outrigger paddle necklace, Dash of Aloha cookbook), a Jeopardy-type game they played as a group to review class material, and food label reading. A young male participant said,

"The label-reading activity is great for young guys. I never learned about reading labels; I just bought whatever my mother bought or whatever was on sale."

Participants explained that they started sharing what they learned with their families. One participant said,

"I know a lot more about diabetes now, and if my father was alive, I could have helped him more, but now I can help my daughter to prevent diabetes."

Another participant said,

"This class really helped and now I'm teaching my grandchildren how to prevent diabetes by making healthy eating choices."

For future interventions, participants recommended cooking classes, meal planning, and adding a diabetes support group after the intervention concluded. They also recommended using culturally based stories to promote healthy eating and physical activity in children and learning ways to discuss diabetes self-management with their employers and colleagues at work. Participants differed in their opinions about the frequency of classes, with recommendations ranging from 2 classes per week to 1 class every 2 weeks. 
Table 3 Participant responses regarding the Partners in Care class content found most useful $(n=314)$

\begin{tabular}{|c|c|}
\hline Response Topic & Participant Responses \\
\hline \multirow{8}{*}{$\begin{array}{l}\text { Diabetes self-management class } \\
\text { content }\end{array}$} & -The role of blood glucose, insulin, and the pancreas in diabetes \\
\hline & $\begin{array}{l}\text { - How self-monitoring can show blood glucose level at any time and can help prevent the consequences of very } \\
\text { high or very low blood glucose }\end{array}$ \\
\hline & -The benefits of diabetes medications, how they control blood glucose, and side effects \\
\hline & -What blood glucose and A1C numbers mean and what they should be to prevent complications \\
\hline & -What my blood pressure numbers mean \\
\hline & ·Good cholesterol versus bad cholesterol \\
\hline & •How to ask family and friends for help with self-management \\
\hline & -Participating in group discussions to share experiences and ideas \\
\hline \multirow[t]{7}{*}{ Diet and physical activity } & -Increased awareness and understanding of relationship between food and blood glucose \\
\hline & -How to read food labels to reduce dietary fat and sugar \\
\hline & -Importance of getting family included in healthy eating and exercise to prevent diabetes \\
\hline & -Alternative cooking methods such as grilling, steaming, baking \\
\hline & •Healthier serving sizes of foods \\
\hline & -The role of physical activity and how it can improve blood glucose, blood pressure, and stress \\
\hline & ·How to incorporate physical activity into everyday activities \\
\hline \multirow[t]{4}{*}{ Complications } & -How diabetes affects nerves and stress level \\
\hline & -How diabetes can affect teeth and gums \\
\hline & -How diabetes can affect the eyes \\
\hline & -Importance of foot care \\
\hline
\end{tabular}

Overall satisfaction with Partners in Care was high, and participants thought that their involvement improved their diabetes self-management. One participant reported,

"I've been to a lot of other diabetes classes, and this one was the best."

Another said,

"This information has empowered me to make better decisions about my diabetes. More knowledge, more power."

One participant observed the positive effects of diabetes self-management in her family, stating,

"My husband is feeling much better after this class."

Participants also reported their appreciation of the peer educators, especially their ability to explain complex concepts in plain language. Peer educators were characterized as "compassionate," "helpful," and "able to present information in a fun and interactive way." They were adept at using local analogies to present information. For example, one peer educator used the analogy of a Hawaiian outrigger canoe to describe participants' role on their diabetes care team. An outrigger canoe seats six paddlers, and all six must work together to reach their destination. The person in seat six is the steersperson who instructs the paddlers and keeps the canoe on course. In this analogy, the person with diabetes is the steersperson who guides the paddlers (i.e., everyone involved in the patient's health and well-being, such as health care providers, relatives, and friends) to achieve his or her self-management goals.

\section{Peer educator implementation outcomes Fidelity}

The mean rating by 2 independent study staff for intervention fidelity was high (4.8 on a scale from 1 to 5 ), indicating that peer educators delivered at least $98 \%$ of the curriculum material as written and conducted 95\% of the proposed activities. Some activities could not be delivered because of time constraints resulting from participants' extended conversations during classes. Research staff impressions of participant understanding of class material was rated high (a mean rating of 4.7 on a scale from 1 to 5), and mean rating of satisfaction with content and activities was 3.8 on a scale from 1 to 4 , indicating high satisfaction. Observers noted that participants appeared to enjoy the curriculum materials and activities as well as the group format. They frequently asked questions, engaged in discussion, and shared stories relevant to the class topic, including their own challenges with 
self-management. Peer educators were able to answer most questions posed by participants, and they appropriately referred participants to their health care providers in cases where they lacked the necessary knowledge or information.

\section{Acceptability, adoption, appropriateness and feasibility}

The main themes reported by the 3 peer educators during the focus group conducted at the end of the intervention were that the intervention materials and activities were culturally appropriate, well organized, easy to facilitate, and relevant for participants. The peer educators reported that participants enjoyed the classes, appreciated the group interaction, and enjoyed the program incentives and healthy snacks. They said that participants talked to friends and family about the program and included their families in efforts to change dietary and physical activity habits to prevent diabetes. Peer educators felt that the class time of $1-1.5 \mathrm{~h}$ per week was adequate, while noting that some participants' attendance was challenged by family responsibilities, work schedules, and class frequency. Another challenge reported by peer educators was related to randomizing participants to groups in which the wait-list group would have to wait 3 months before receiving the intervention.

\section{Sustainability}

After the intervention concluded, one of our clinic partners adopted Partners in Care as their standard diabetes self-management education program. From 2012 to 2014, funding from the National Institutes of Minority Health and Health Disparities provided the opportunity to disseminate Partners in Care to health care and community organizations throughout Oahu. Trainings were delivered by the Partners in Care peer educators. After the training, 2 community clinics adopted Partners in Care as their standard DSMES program that is now being delivered to all patients with diabetes in those clinics. Each of the clinics have American Diabetes Association recognition as a diabetes program and are being reimbursed by Medicare for delivery of Partners in Care (2016 He Huliau Conference presentation, Honolulu, Hawaii, and personal communication with diabetes program clinic staff). In addition, one of these clinics requires medical residents to attend some of the Partners in Care classes to learn from participants their challenges with diabetes self-management. Finally, 1 community research site implemented Partners in Care a second time and offered a support group for participants to meet once per month for 6 months following the intervention.

\section{Discussion}

Partners in Care used a community-based participatory approach to culturally adapt, implement, and evaluate an evidence-based DSMES intervention with NHPIs residing in Honolulu, Hawai'i. It is one of only a few studies that included NHPIs in a randomized controlled trial to evaluate the effectiveness of a peer-delivered DSMES intervention [28] and implementation outcomes. In 2016, we implemented another pilot of Partners in Care to evaluate the addition of social support alone offered after the intervention. As in the first pilot study, [28] participants showed significant improvement in A1C after the DSMES intervention, although there was no added benefit to A1C from subsequent social support [34]. Another implementation of Partners in Care with Latino adults demonstrated significant improvement in A1C compared to a control group and improvements in A1C were maintained at 18 months [35].

Several factors may help explain the positive results of the Partners in Care study. First, our study suggests that the use of peer educators contributed to cultural and local adaptations, retention, and active engagement of participants in the classes. Peer educators were trained to conduct interactive and constructive classes in which participants learned self-management strategies and how to put them into practice in the context of everyday life. Several studies support the use of peer educators to help patients manage their diabetes because their involvement has been shown to improve patients' glycemic control and reduce healthcare use [36, 37]. Second, the intervention was culturally tailored with the help of local peer educators and a NHPI Steering Committee increasing the relevance of study materials. Third, the study approach incorporated and emphasized behavioral strategies and psychosocial dimensions that considered the context in which diabetes is dealt with on a daily basis [32] as opposed to traditional didactic teaching. Finally, retention was relatively high, with attrition higher among younger age participants. Family obligations and work schedules were the most frequently reported reasons for missing Partners in Care classes. Research on differing topics have also encountered higher attrition among younger participants [38-40]. Lack of sustained participation by younger individuals with type 2 diabetes is particularly concerning because the rate of decline in $\beta$-cell function appears to be more rapid [41] which contributes to premature microvascular (nephropathy, retinopathy and neuropathy) and macrovascular (cardiovascular) complications $[42,43]$. Few studies have examined the pathophysiological mechanisms that contribute to the decline in $\beta$-cell function among young people [42]. Future DSMES programs should consider these demands when they schedule classes and other activities. Alternate methods of intervention delivery, such as on-line classes or technology-based 
interventions, may be more convenient for younger individuals who have busy work and family schedules.

Adoption and institutionalization in 3 community clinics in Hawaii has continued through 2020 and demonstrates the long-term sustainability of Partners in Care. It should be noted that these clinics are accredited diabetes programs and have the capacity to bill the Centers for Medicare and Medicaid (CMS) and individual insurance plans for the delivery of Partners in Care to patients. Achieving recognition as a diabetes program by the American Diabetes Association [44] or the Association of Diabetes Care and Education Specialists (ADCE S) [45] in order to seek reimbursement for services through CMS requires several steps that may be more easily realized within healthcare institutions. For example, these recognition programs require a healthcare professional, such as a nurse educator, registered dietician, or certified diabetes educator to deliver the DSMES for reimbursement and do not allow community health workers to do so. In our study, the Federally Qualified Health clinic had a registered dietician deliver Partners in Care. This was the only study site that was an ADCES-recognized diabetes program and adopted Partners in Care as their standard DSMES after the study. Challenges to sustainability of Partners in Care and similar programs exist in settings where it may be uncommon to have mechanisms in place to request reimbursement for such services. The inability to financially support delivery of effective interventions may impede the sustainability of beneficial and effective programs in non-clinic settings.

Despite high participant satisfaction and positive results, the study has limitations. First, the high proportion of positive responses in the end-of-class surveys may reflect the voluntary nature of both the classes and the evaluation. While the surveys were anonymous, small group size and the relationship with the peer educator may have contributed to socially desirable responses. Second, fidelity during class observations may have been higher due to the study staff present at select classes. Third, some data elements, such as acceptability, adoption, and appropriateness, reported for participants may seem to overlap with those for peer educators. However, the definitions are differentiated for those elements that are the same for participants and peer educators. Fourth, the sample size in this pilot study was small and findings may not be generalizable to other NHPIs. Finally, implementation costs or cost effectiveness of the intervention was not assessed. However, delivery of interventions by peer educators in community settings typically cost less than delivery by licensed health professionals in clinical settings [46]. Although, sustained implementation of Partners in Care is being reimbursed within 3 clinical settings and may be cost effective. Without funding or mechanisms to reimburse services delivered by peer educators, sustained implementation of some programs may not be feasible in community settings. Future research should explore cost effectiveness in different settings and policies to increase reimbursement for services delivered by trained peer educators. The field of DSMES is dynamic, and approaches are constantly evolving. Further research is needed to identify effective programs to reduce diabetes-related disparities experienced by NHPI.

\section{Conclusions}

Results from this research supports a culturally tailored, peer educator approach to DSMES among NHPIs. Understanding factors that affect implementation and adoption of self-management behaviors can inform effective approaches to improve health outcomes among NHPIs. Delivery of the Partners in Care program is feasible in health care and community settings and is a reimbursable DSMES program.

\section{Supplementary information}

The online version contains supplementary material available at https://doi. org/10.1186/s12889-020-09690-6.

Additional file 1. Partners in Care participant baseline survey. The Partners in Care baseline clinical, demographic, knowledge, and behavioral survey.

\section{Abbreviations}

DSMES: Diabetes self-management education and support; NHPI: Native Hawaiians and Pacific Islanders; A1C: Hemoglobin A1C; CMS: Centers for Medicare and Medicaid (CMS); ADCES: Association of Diabetes Care and Education Specialists (ADCES)

\section{Acknowledgments}

We are grateful to the study participants, the community researchers and peer educators who supported implementation of the Partners in Care intervention. The authors thank our community partners Ke Ola Mamo, Kula no nā Po'e Hawai'i, and Kōkua Kalihi Valley Comprehensive Family Services for their guidance and participation.

\section{Authors' contributions}

KAS, CTI, and JKK analyzed and interpreted the study data. AZK and PAM were major contributors in writing the manuscript. All authors read and approved the final manuscript.

\section{Funding}

This work was supported by the National Institute on Minority Health and Health Disparities (grant number R24MD001660) of the National Institutes of Health and the National Institute of Diabetes, Digestive, and Kidney Diseases (grant number K01DK090091). The content is solely the responsibility of the authors and does not necessarily represent the official views of the National Center on Minority Health and Health Disparities or the National Institutes of Health. The funding bodies had no part in the design of the study and collection, analysis, and interpretation of data or in writing the manuscript.

\section{Availability of data and materials}

The datasets generated and/or analyzed during the current study are not publicly available because they contain data collected from individuals who were recruited from partnering Native Hawaiian-serving organizations. These organizations provide oversight of data collected from Native Hawaiians in this study for purposes other than this study. Data may be available from the corresponding author and the partnering Native Hawaiian organizations on reasonable request. 


\section{Ethics approval and consent to participate}

The study protocol was approved by the University of Hawai'i Committee on Human Studies and the Native Hawaiian Health System Institutional Review Board. Written informed consent was obtained from participants prior to their participation in the study.

\section{Consent for publication}

Not applicable.

\section{Competing interests}

The authors declare that they have no competing interests.

\section{Author details}

${ }^{1}$ Institute for Research and Education to Advance Community Health, College of Nursing, Washington State University, 1100 Olive Way, Suite 1200, Seattle, WA 98101, USA. ${ }^{2}$ Institute for Research and Education to Advance Community Health, Washington State University, 1100 Olive Way, Suite 1200, Seattle, WA 98101, USA. ${ }^{3}$ Department of Native Hawaiian Health, John A. Burns School of Medicine, University of Hawai' i, 677 Ala Moana Blvd, Suite 1016, Honolulu, Hawai'i 96813, USA. ${ }^{4}$ University of Arkansas Medical Sciences, 1125 N. College Avenue, Fayetteville, AR 72703-1908, USA.

Received: 31 March 2020 Accepted: 13 October 2020 Published online: 20 October 2020

\section{References}

1. Foliaki S, Pearce N. Prevalence and causes of diabetes in Pacific people. Pac Health Dialog. 2003;10(2):90-8.

2. Communities EPI. Native Hawaiians and Pacific islanders in the United States: a community of contrasts 2014. Los Angeles; 2014.

3. Mau MK, Sinclair K, Saito EP, Baumhofer KN, Kaholokula JK. Cardiometabolic health disparities in native Hawaiians and other Pacific islanders. Epidemiol Rev. 2009;31:113-29.

4. Karter AJ, Schillinger D, Adams AS, Moffet HH, Liu J, Adler NE, et al. Elevated rates of diabetes in Pacific islanders and Asian subgroups: the diabetes study of northern California (DISTANCE). Diabetes Care. 2013;36(3):574-9.

5. Kanaya A, Adler N, Moffet H, Liu J, Schillinger D, Adams AS, et al. Heterogeneity of diabetes outcomes among Asians and Pacific islanders in the US: the diabetes study of northern California (DISTANCE). Diabetes Care. 2011;34(4):930-7.

6. TransPacific Renal Network. TransPacific Renal Network: Selected Demographics 2000. San Rafael, CA; 2001.

7. Mitigating the Burden of Type 2 Diabetes: Challenges and Opportunities. Am Health Drug Benefits. 2015;8(2 Suppl 1):S3-11.

8. Adam L, O'Connor C, Garcia AC. Evaluating the impact of diabetes selfmanagement education methods on knowledge, attitudes and Behaviours of adult patients with type 2 diabetes mellitus. Can J Diabetes. 2018;42(5): 470-7 e2.

9. American Diabetes Association. Standards of medical care in diabetes - 2020. Diabetes Care. 2020;43:S1-S212.

10. United Kingdom Prospective Diabetes Study Group (UKPDS). Intensive blood glucose control with sulphonylureas or insulin compared with conventional treatment and risk of complications in patients with type 2 diabetes. Lancet. 1998;352:837-53.

11. Nathan D, DCCT/EDIC Research Group. The diabetes control and complications trial/epidemiology of diabetes interventions and complications study at 30 years: overview. Diabetes Care. 2014;37(1):9-16.

12. Beck J, Greenwood DA, Blanton L, Bollinger ST, Butcher MK, Condon JE, et al. 2017 National Standards for diabetes self-management education and support. Diabetes Educ. 2020;46(1):46-61.

13. Black N, Nabokov V, Vijayadeva V, Novotny R. Higher percent body fat in young women with lower physical activity level and greater proportion Pacific islander ancestry. Hawaii Med J. 2011;70(11 Suppl 2):43-6.

14. Madan A, Archambeau OG, Milsom VA, Goldman RL, Borckardt JJ, Grubaugh $\mathrm{AL}$, et al. More than black and white: differences in predictors of obesity among native Hawaiian/Pacific islanders and European Americans. Obesity (Silver Spring). 2012;20(6):1325-8.

15. McEligot AJ, McMullin J, Pang K, Bone M, Winston S, Ngewa R, et al. Diet, psychosocial factors related to diet and exercise, and cardiometabolic conditions in southern Californian native Hawaiians. Hawaii Med J. 2010; 69(5 Suppl 2):16-20.
16. Moy KL, Sallis JF, David KJ. Health indicators of native Hawaiian and Pacific islanders in the United States. J Commun Health. 2010;35(1):81-92.

17. Moy KL, Sallis JF, Trinidad DR, Ice CL, McEligot AJ. Health behaviors of native Hawaiian and Pacific islander adults in California. Asia Pac J Public Health. 2012;24(6):961-9.

18. Erber E, Hopping BN, Grandinetti A, Park SY, Kolonel LN, Maskarinec G. Dietary patterns and risk for diabetes: the multiethnic cohort. Diabetes Care. 2010;33(3):532-8.

19. Peters D, Adam T, Alonge O, Akua Agyepong I, Tran N. Implementation research: what it is and how to do it. BMJ. 2013:347.

20. Theobald S, Brandes N, Gyapong M, El-Saharty S, Proctor E, Diaz T, et al. Implementation research: new imperatives and opportunities in global health. Lancet. 2018;392(10160):2214-28.

21. Tabak R, Sinclair K, Baumann A, Racette S, Kuhlmann A, Johnson-Jennings $M$, et al. A review of diabetes prevention program translations: use of cultural adaptation and implementation research. Transl Behav Med. 2015; 5(4):401-14.

22. Elliott D, Mihalic S. Issues in disseminating and replicating effective prevention programs. Prev Sci. 2004;5(1):47-53.

23. Proctor $E$, Silmere $H$, Raghavan $R$, Hovmand $P$, Aarons $G$, Bunger $A$, et al. Outcomes for implementation research: conceptual distinctions, measurement challenges, and research agenda. Admin Pol Ment Health. 2011;38(2):65-76.

24. Gilliland S, Azen S, Perez G, Carter J. Strong in body and Spirit: lifestyle intervention for native American adults with diabetes in New Mexico. Diabetes Care. 2002;25(1):78-83.

25. Two Feathers J, Kieffer EC, Palmisano G, Anderson M, Sinco B, Janz N, et al. Racial and ethnic approaches to community health (REACH) Detroit partnership: improving diabetes-related outcomes among African American and Latino adults. Am J Public Health. 2005;95(9):1552-60.

26. Kaholokula JK, Ing CT, Look MA, Delafield R, Sinclair K. Culturally responsive approaches to health promotion for native Hawaiians and Pacific islanders. Ann Hum Biol. 2018;45(3):249-63.

27. Two Feathers J, Kieffer E, Palmisano G, Anderson M, Janz N, Spencer M, et al. The development, implementation, and process evaluation of the REACH Detroit Partnership's diabetes lifestyle intervention. Diabetes Educ. 2007;33:509-20.

28. Sinclair K, Makahi E, Shea-Solatorio C, Yoshimura S, Townsend C, Kaholokula J. Outcomes from a diabetes self-management intervention for native Hawaiians and Pacific people: Partners in Care. Ann Behav Med. 2012;45(1):24-32.

29. Kieffer EC, Willis SK, Odoms-Young AM, Guzman JR, Allen AJ, Two Feathers $J$, et al. Reducing disparities in diabetes among African-American and Latino residents of Detroit: the essential role of community planning focus groups. Ethn Dis. 2004;14(3 Suppl 1):S27-37.

30. Kaholokula JK, Wilson RE, Townsend CK, Zhang GX, Chen J, Yoshimura SR, et al. Translating the diabetes prevention program in native Hawaiian and Pacific islander communities: the PILI 'Ohana project. Transl Behav Med. 2014;4(2):149-59.

31. American Diabetes Association. Standards of medical Care in Diabetes. Diabetes Care. 2010;33(Suppl 1):S11-61.

32. Bandura A. Social foundations of thought and action: a social cognitive theory. Englewood Cliffs, NJ: Prentice Hall; 1986.

33. Miles M, Huberman M. Qualitative data analysis: an expanded sourcebook. 2nd ed. Thousand Oaks, CA: Sage; 1994.

34. Ing CT, Zhang G, Dillard A, Yoshimura SR, Hughes C, Palakiko DM, et al. Social support groups in the maintenance of glycemic control after community-based intervention. J Diabetes Res. 2016;2016:7913258.

35. Spencer MS, Kieffer EC, Sinco B, Piatt G, Palmisano G, Hawkins J, et al. Outcomes at 18 months from a community health worker and Peer leader diabetes self-management program for Latino adults. Diabetes Care. 2018; 41(7):1414-22.

36. Community Preventive Services Task Force. Diabetes Management: Interventions Engaging Community Health Workers 2017 [Available from: https://www.thecommunityguide.org/findings/diabetes-managementinterventions-engaging-community-health-workers.

37. Werfalli M, Raubenheimer P, Engel M, Peer N, Kalula S, Kengne AP, et al. Effectiveness of community-based peer-led diabetes self-management programmes (COMP-DSMP) for improving clinical outcomes and quality of life of adults with diabetes in primary care settings in low and middleincome countries (LMIC): a systematic review and meta-analysis. BMJ Open. 2015;5(7):e007635. 
38. Cannon M, Masalovich S, Ng B, Soler R, Jabrah R, Ely E, et al. Retention Among Participants in the National Diabetes Prevention Program Lifestyle Change Program, 2012-2017. Diabetes Care. 2020;43(9):-2042.

39. Wills CJ, Scott A, Swift PG, Davies MJ, Mackie AD, Mansell P. Retrospective review of care and outcomes in young adults with type 1 diabetes. BMJ. 2003:327(7409):260-1.

40. Young A, Powers J, Bell S. Attrition in longitudinal studies: who do you lose? Aust N Z J Public Health. 2006;30:353-61.

41. Gungor N, Arslanian S. Progressive beta cell failure in type 2 diabetes mellitus of youth. J Pediatr. 2004;144(5):656-9.

42. Song S. Emerging type 2 diabetes in young adults. Adv Exp Med Biol. 2012; 771:51-61.

43. Hillier T, Pedula K. Complications in young adults with early-onset type 2 diabetes: losing the relative protection of youth. Diabetes Care. 2003;26(11): 2999-3005.

44. American Diabetes Association. Education Recognition Requirements 10th Edition Arlington, VA: American Diabetes Association; 2017 [Available from: https://professional.diabetes.org/sites/professional.diabetes.org/files/media/ erp-10th-edition-recognition-requirements.pdf.

45. American Association of Diabetes Educators. Diabetes Education Accreditation Program Chicago, IL: American Association of Diabetes Educators; 2017 [Available from: https://www.diabeteseducator.org/practice/ diabetes-education-accreditation-program-(deap)/applying-for-accreditation.

46. Vaughan K, Kok MC, Witter S, Dieleman M. Costs and cost-effectiveness of community health workers: evidence from a literature review. Hum Resour Health. 2015;13:71.

\section{Publisher's Note}

Springer Nature remains neutral with regard to jurisdictional claims in published maps and institutional affiliations.

Ready to submit your research? Choose BMC and benefit from:

- fast, convenient online submission

- thorough peer review by experienced researchers in your field

- rapid publication on acceptance

- support for research data, including large and complex data types

- gold Open Access which fosters wider collaboration and increased citations

- maximum visibility for your research: over $100 \mathrm{M}$ website views per year

At BMC, research is always in progress.

Learn more biomedcentral.com/submissions 